\title{
Modification of Polyolefins with Silicone Copolymers. I. Processing Behavior and Surface Characterization of PP and HDPE Blended with Silicone Copolymers
}

\author{
ISKENDER YILGOR, ${ }^{1}$ EMEL YILGOR, ${ }^{1}$ SEFIK SUZER ${ }^{2}$ \\ ${ }^{1}$ Chemistry Department, Koc University, Sariyer 80910 Istanbul, Turkey \\ ${ }^{2}$ Chemistry Department, Bilkent University, 06533 Ankara, Turkey
}

Received 9 January 2001; accepted 12 March 2001

\begin{abstract}
Permanent surface modification of polypropylene and high-density polyethylene was obtained by blending with small ( 0.1 to $5.0 \%$ by weight) amounts of silicone copolymers. A triblock polycaprolactone- $b$-polydimethylsiloxane copolymer and a multiblock polydimethylsiloxane-urea copolymer were used as modifiers. Blends were prepared in a twin-screw extruder. Influences of the type and amount of the additive on the processing behavior and surface and bulk properties of the resulting systems were investigated. During processing, the additives also acted as very efficient processing aids, increasing the extruder output dramatically, up to $200 \%$. Surface characterization by water-contact angle measurements and X-ray photoelectron spectroscopy clearly showed the formation of silicone-rich surfaces even with very small amounts of additives, such as 0.1\% by weight. ( 2002 John Wiley \& Sons, Inc. J Appl Polym Sci 83: 1625-1634, 2002
\end{abstract}

Key words: polyolefins; extrusion; surface modification; silicone copolymers

\section{INTRODUCTION}

Recent advances in controlled polymerization of olefin monomers through the use of metallocene catalysts have resulted in the preparation of welldefined polyolefins with tailored chemical structures, tacticities, morphologies, and bulk properties. As a result, especially isotactic polypropylene (PP) and to some extent high-density polyethylene (HDPE) now find uses in many applications such as automotive, appliances, and computers, replacing other conventional commodity plastics such as ABS, HIPS, and PVC. In many industrial applications of polymeric materials, several criteria play important roles in the selection of the resins. In terms of overall performance,

Correspondence to: I. Yilgor.

Journal of Applied Polymer Science, Vol. 83, 1625-1634 (2002)

(๑) 2002 John Wiley \& Sons, Inc.

DOI 10.1002/app.10066 these generally include (1) the bulk properties, (2) the surface properties, and (3) the processibility of the resin. Bulk properties are critical in determining the thermal behavior and mechanical strength of polymers. ${ }^{1,2}$ On the other hand, surface properties play important roles in determining the wettability and adhesion, friction and wear, gloss and scratch resistance, paintability and printability, biocompatibility, and antistatic properties. ${ }^{3,4}$ Other important criteria in the selection of polymeric resins for various applications are their ease of processibility and compounding. Depending on the application, to improve the bulk or surface properties or processibility of polymeric resins a wide range of additives are used during compounding, extrusion, or molding. ., $^{5}$

Polydimethylsiloxane (PDMS)-containing copolymers display an unusual combination of properties. These include extremely low glass-transi- 
tion temperatures of $-120^{\circ} \mathrm{C}$; very low surface energies; good thermal, UV, and flame resistance; water repellancy; hydrolytic stability; and biocompatibility. ${ }^{7}$ Silicone (PDMS)-containing copolymers display two-phase morphologies that are attributed to major differences between the solubility parameters of organic segments and PDMS. ${ }^{8,9}$ In addition, because of their very low surface energies (21-22 mN/m), PDMS segments in these copolymers tend to migrate to the polymer-air interface, leading to the formation of very low energy surfaces. ${ }^{10,11}$ When PDMS-containing block copolymers are blended with other organic polymers they show similar bulk and surface behavior. If the organic blocks and PDMS segments are properly designed it is possible to use these silicone copolymers as surface-modifying additives for organic polymers. In such systems organic blocks interact with the base resin through entanglements, cocrystallization, or electrostatic interaction, such as hydrogen bonding, whereas silicone segments provide the surface modification. ${ }^{12,13}$ When such additives are used in small amounts, the change in surface properties is achieved without influencing the bulk morphology or properties of the base resin. In view of the preceding observations, it is possible to optimize the application-specific surface properties of a polymeric system by proper choice of a base resin with the desired bulk properties and a surfacemodifying silicone copolymer and blending them before processing.

In this study two silicone copolymers, a polydimethylsiloxane- $b$-polycaprolactone triblock copolymer (PCL-PDMS-PCL) and a polydimethylsiloxane-urea (PSU) segmented copolymer were used in the surface modification of PP and HDPE by blending. The blends were prepared in a twinscrew extruder. The amount of silicone copolymer additive used varied between 0.1 and $5 \%$ by weight. In addition to modifying the surface properties of PP and HDPE, as expected, these silicone copolymers also functioned as effective processing aids during the extrusion process. Influences of the type and amount of the additive on processing parameters and extruder output were investigated. Thermal, mechanical, and surface properties of the materials obtained were determined. It was clearly demonstrated that permanent surface modification was achieved without influencing the bulk properties of base resins. Detailed surface characterization of the modified polyolefin films was obtained by water-contact angle measurements, X-ray photoelectron spectroscopy
(XPS or ESCA), and various tribological techniques. Results on the thermal and mechanical properties and tribological behavior of siliconemodified PP and HDPE are reported in a companion study. ${ }^{14}$

\section{EXPERIMENTAL}

\section{Materials}

Polypropylene (Profax 6523) was obtained from Himont, USA. High-density polyethylene (4532 NT) was a product of Dow Chemical, USA. Silicone-caprolactone triblock copolymer (PCLPDMS-PCL) with PDMS block length of 2500 $\mathrm{g} / \mathrm{mol}$ and PCL block lengths of $2000 \mathrm{~g} / \mathrm{mol}$ was obtained from Goldschmidt AG (Essen, Germany). 4,4'-Isocyanatocyclohexylmethane (HMDI) was supplied by Bayer AG. $\alpha, \omega$-Aminopropyl terminated polydimethylsiloxane oligomers with molecular weights of $900 \mathrm{~g} / \mathrm{mol}$ (PDMS-900) and $21,000 \mathrm{~g} / \mathrm{mol}$ (PDMS-21000) were prepared by equilibration techniques. ${ }^{8}$ Silicone-urea (PSU) segmented copolymer was prepared in a twinscrew extruder according to the procedure described below.

\section{Extrusion Equipment}

A self-wiping, corotating, 30-mm twin-screw extruder (Werner-Pfleiderer ZSK-30, Ramsey, NJ) with an $L / D$ ratio of 42 was used during the blending and polymerization experiments. The instrument had six heating zones, three injection ports fitted with precision Lewa pumps (Holliston, MA), and a vacuum outlet. Strands of polymer melt obtained were passed through a water bath and pelletized.

\section{Preparation of Silicone-Urea Copolymer in the Extruder}

Amine-terminated silicone oligomers PDMS21000 and PDMS-900 were mixed at a weight ratio of $3 / 1$ to produce a homogeneous mixture. The number-average molecular weight of the blend determined by $\mathrm{HCl}$ titration was 3190 $\mathrm{g} / \mathrm{mol}$. PDMS mixture was fed into the extruder through a precision pump at the rate of $69.3 \mathrm{~g} / \mathrm{min}$ (21.7 $\mathrm{mmol} / \mathrm{min})$. HMDI was fed into the extruder at the same point through a separate pump, at a rate of $5.7 \mathrm{~g} / \mathrm{min}(21.7 \mathrm{mmol} / \mathrm{min})$, to produce stoichiometric balance between amine and isocyanate, which was monitored by FTIR spectroscopy. 
The barrel temperature was set at $100^{\circ} \mathrm{C}$ at the feeding zone and was gradually increased to $200^{\circ} \mathrm{C}$. The screw speed was kept constant at 40 $\mathrm{rpm}$. The FTIR spectrum obtained from the polymer melt showed complete disappearance of the isocyanate group, which has a strong absorption peak at $2260 \mathrm{~cm}^{-1}$. Strands of high molecular silicone-urea polymer obtained were cooled in a water bath, air-dried, and pelletized. Pellets obtained were further dried in a vacuum oven at $50^{\circ} \mathrm{C}$ for $48 \mathrm{~h}$. Composition of the PSU copolymer thus obtained (by weight) was as follows: PDMS21000 (69.3\%), PDMS-900 (23.0\%), and HMDI $(7.7 \%)$.

\section{Blending Procedure}

Base resins and the additives were first dryblended at the desired amounts and then fed into the extruder through a K-Tron (Pitman, NJ) lossin-weight feeder. Zone temperatures were varied between 150 and $185^{\circ} \mathrm{C}$ for HDPE and 175 and $220^{\circ} \mathrm{C}$ for PP blends. Strands of polymer melt obtained were water cooled, air dried, and pelletized. Pellets were dried in a vacuum oven at $50^{\circ} \mathrm{C}$ and kept in sealed polyethylene bags until further characterization. Extruder output was determined with an analytical balance.

\section{Characterization Techniques}

Film samples with dimensions of $5.0 \times 5.0 \times 0.1$ $\mathrm{cm}$, to be used for water-contact angle measurements, were compression molded between stainless-steel plates, by using a Carver hydraulic press (Menomonee Falls, WI). Molding temperatures for HDPE- and PP-containing systems were 180 and $210^{\circ} \mathrm{C}$, respectively. Stainless-steel plates were thoroughly cleaned by successive washing with dimethylformamide, tetrahydrofuran, and methylene chloride before use. Compression-molded films were kept in sealed polyethylene bags in a dessicator until further characterization. Static water-contact angle measurements were performed on a Kruss G-10 goniometer (Hamburg, Germany), at room temperature, using deionized and triple-distilled water. The volume of water droplet was $20 \mu \mathrm{L}$. On average 7 to 10 readings were taken for each sample. FTIR spectra of very thin films were recorded on a Nicolet Impact 400D spectrometer (Nicolet Instruments, Madison, WI) at a resolution of 2 $\mathrm{cm}^{-1}$. XPS spectra of films (obtained by direct melting of virgin materials and blends on metal probes) were recorded using a Kratos ES 300 electron spectrometer (Chestnut Ridge, NY) using $\mathrm{MgK} X$-rays at $1253.6 \mathrm{eV}$. The films were inserted into the vacuum system with a base pressure of less than $10^{-8}$ mbar and were analyzed directly.

\section{RESULTS AND DISCUSSION}

For many applications the overall performance of polymeric materials is dependent on the balance between their bulk and surface properties and their ease of processibility. Thermal behavior and mechanical integrity of polymers are typical bulk properties that depend on their chemical structure (composition), polymer architecture, and resulting bulk morphologies, which are usually dictated during their chemical production. Generally it is possible to improve the bulk properties of a polymeric material through the use of reinforcing fillers, such as carbon black or short glass fibers. Surface properties, on the other hand, are more difficult to control and are usually provided by the

Table I Influence of PCL-PDMS-PCL Copolymer Additive on Various Processing Parameters and Extruder Output During the Processing of PP in a Twin-Screw Extruder

\begin{tabular}{ccccc}
\hline $\begin{array}{c}\text { Additive Level } \\
\text { (\% by weight) }\end{array}$ & $\begin{array}{c}\text { PDMS } \\
(\text { wt \%) }\end{array}$ & $\begin{array}{c}\text { Screw Speed } \\
(\mathrm{rpm})\end{array}$ & $\begin{array}{c}\text { Torque } \\
(\mathrm{amp})\end{array}$ & $\begin{array}{c}\text { Extruder Output } \\
(\mathrm{g} / \mathrm{min})\end{array}$ \\
\hline- & - & 250 & 21 & 81 \\
0.10 & 0.04 & 275 & 21 & 109 \\
0.25 & 0.10 & 275 & 21 & 120 \\
0.50 & 0.19 & 350 & 20 & 149 \\
1.00 & 0.38 & 350 & 20 & 180 \\
2.50 & 0.96 & 400 & 19 & 182 \\
5.00 & 1.92 & 400 & 17 & \\
\hline
\end{tabular}


Table II Influence of PSU Copolymer Additive on Processing Parameters and Extruder Output During the Processing of PP in a Twin-Screw Extruder

\begin{tabular}{ccccc}
\hline $\begin{array}{c}\text { Additive Level } \\
(\% \text { by weight })\end{array}$ & $\begin{array}{c}\text { PDMS } \\
(\text { wt \% })\end{array}$ & $\begin{array}{c}\text { Screw Speed } \\
(\mathrm{rpm})\end{array}$ & $\begin{array}{c}\text { Torque } \\
(\mathrm{amp})\end{array}$ & $\begin{array}{c}\text { Extruder Output } \\
(\mathrm{g} / \mathrm{min})\end{array}$ \\
\hline- & - & 250 & 21 & 81 \\
0.10 & 0.09 & 350 & 24 & 150 \\
0.25 & 0.23 & 350 & 23 & 170 \\
0.50 & 0.46 & 400 & 23 & 190 \\
1.00 & 0.92 & 400 & 23 & 190 \\
2.50 & 2.31 & 400 & 23 & 200 \\
\hline
\end{tabular}

use of additives during processing or by various physical or chemical surface-coating techniques after processing. ${ }^{3,6,16}$ Processibility depends on factors such as molecular structure and architecture, overall polymer molecular weight, and molecular weight distribution. In many cases various additives can be used to improve the processibility of polymeric materials. ${ }^{5}$

Polymers with controlled surface properties have always been a very important field of research for both academic and industrial laboratories. This is mainly because of the fact that most of the performance-based properties of polymeric materials are surface related. These include environmental resistance (thermal, oxidative, and UV stability), adhesion (printability and paintability), fire and flame resistance, antistatic properties, friction and wear resistance, and biocompatibility. In general most of the polymers with desired bulk properties for a specific application do not have the desired surface properties. Sur-

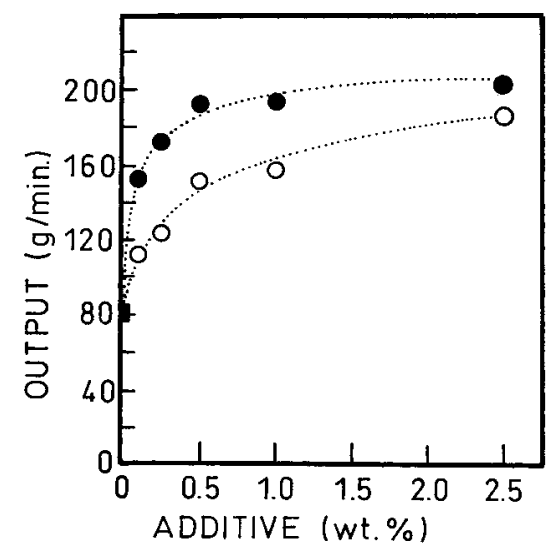

Figure 1 Extruder output as a function of the type and amount of silicone copolymer additive in PP blends. (○) PCL-PDMS-PCL, (๑) PDMS-PU additive. face properties of polymers are usually modified through the use of specific additives during the processing or by various surface-coating techniques such as corona or plasma treatment, chemical grafting onto the surface, flame treatment, or other types of topical coatings. ${ }^{3,4,6,16} \mathrm{~A}$ simpler but effective method of polymer surface modification is the use of surface-active copolymers, which may be blended with the base polymer in small amounts before processing and migrate to the polymer-air surface after processing. Depending on the type, nature, molecular weight, and amount of the additive, with this technique it is possible to obtain both low-energy and highenergy surfaces. ${ }^{10-13,17}$ Silicone-containing copolymers are frequently used for the surface modification of various polymers, especially in applications in which hydrophobicity, low surface friction, and/or biocompatibility are required. ${ }^{8,18}$

\section{Influence of Silicone-Copolymer Additives on Processing Behavior of Polyolefins}

During the extrusion or melt processing of polymeric resins, low molecular weight polyolefin or polyamide waxes and silicone oils are usually employed as lubricants, processing aids, and/or flow promoters. These additives usually improve the flow characteristics of the molten polymer in the extruder barrel by reducing the adhesion or interaction between the polymer and the barrel walls. Therefore, the overall result of the use of these additives is to improve the extruder output by improving the polymer flow. Our main aim in this project was to obtain permanent surface modification in polyolefins through blending with silicone copolymers for use as biomaterials or release films. Given the remarkable improvements observed in the processing conditions and extruder 
Table III Influence of the Level of PCL-PDMS-PCL Copolymer Additive on Various Processing Parameters and Extruder Output During the Processing of HDPE in a Twin-Screw Extruder

\begin{tabular}{ccccc}
\hline $\begin{array}{c}\text { Additive Level } \\
(\% \text { by weight })\end{array}$ & $\begin{array}{c}\text { PDMS } \\
(\text { wt } \%)\end{array}$ & $\begin{array}{c}\text { Screw Speed } \\
(\mathrm{rpm})\end{array}$ & $\begin{array}{c}\text { Torque } \\
\text { (amp) }\end{array}$ & $\begin{array}{c}\text { Extruder Output } \\
(\mathrm{g} / \mathrm{min})\end{array}$ \\
\hline- & - & 250 & 35 & 73 \\
0.1 & 0.04 & 250 & 35 & 80 \\
0.5 & 0.19 & 275 & 35 & 95 \\
1.0 & 0.38 & 275 & 35 & 108 \\
2.5 & 0.96 & 350 & 30 & 143 \\
5.0 & 1.92 & 350 & 25 & 180 \\
\hline
\end{tabular}

output, we discuss these results before going into the details of surface characterization and surface properties.

Tables I and II give the resin compositions in terms of both total additive amount and total PDMS (in wt \%) and extrusion parameters for PCL-PDMS-PCL and PSU-modified PP, respectively. Under normal conditions virgin $\mathrm{PP}$ was extruded between 175 and $220^{\circ} \mathrm{C}$, at a screw speed of $250 \mathrm{rpm}$. This generated a torque reading of $21 \mathrm{amp}$ and an output of $81 \mathrm{~g} / \mathrm{min}$ or approximately $11 \mathrm{lb} / \mathrm{h}$. When only $0.10 \%$ by weight of PCL-PDMS-PCL copolymer (or $0.038 \%$ by weight of PDMS) was added into the system, there was a sudden drop in the torque reading. To keep the torque constant around $21 \mathrm{amp}$, the screw speed was increased to $275 \mathrm{rpm}$. This resulted in an output rate of $109 \mathrm{~g} / \mathrm{min}$ or an improvement of about 35\%, which is substantial. When the level of additive was increased to $0.25 \%$ by weight $(0.10 \%$ PDMS), it was possible to achieve the same torque reading at $275 \mathrm{rpm}$ screw speed. The improvement in the output rate was about $48 \%$. When the additive amount was further increased to $0.50 \%$ by weight or higher it was not possible to achieve a torque reading of 21 amp. At $0.50 \%$ additive level with a screw speed of $350 \mathrm{rpm}$ a torque value of $20 \mathrm{amp}$ and an extruder output of $149 \mathrm{~g} / \mathrm{min}$ were achieved. The improvement in the output was $85 \%$. As the amount of additive was increased to $2.50 \%$ by weight $(0.96 \%$ PDMS), at $400 \mathrm{rpm}$ screw speed, the extruder output showed a maximum at 180 $\mathrm{g} / \mathrm{min}$ at a torque reading of $19 \mathrm{amp}$. The improvement in the extruder output was more than $120 \%$, which is extremely high. When the amount of PCL-PDMS-PCL additive was increased to 5.0\% by weight, no further improvement in the extruder output was observed.

In terms of extrusion efficiency even better results were obtained when high molecular weight PSU copolymers were used as the modifier. At $0.10 \%$ by weight of the additive and at $350 \mathrm{rpm}$ screw speed the extruder output was determined to be $150 \mathrm{~g} / \mathrm{min}$, showing an $85 \%$ improvement. When the amount of PSU was increased to $0.25 \%$ by weight the output was $170 \mathrm{~g} / \mathrm{min}$, indicating $110 \%$ improvement. At PSU additive levels of $0.50 \%$ or above, extruder output reached a plateau at about $190-200 \mathrm{~g} / \mathrm{min}$, indicating an im-

Table IV Influence of the Level of PSU Copolymer Additive on Various Processing Parameters and Extruder Output During the Processing of HDPE in a Twin-Screw Extruder

\begin{tabular}{ccccc}
\hline $\begin{array}{c}\text { Additive Level } \\
(\% \text { by weight })\end{array}$ & $\begin{array}{c}\text { PDMS } \\
(\text { wt \% })\end{array}$ & $\begin{array}{c}\text { Screw Speed } \\
(\mathrm{rpm})\end{array}$ & $\begin{array}{c}\text { Torque } \\
(\mathrm{amp})\end{array}$ & $\begin{array}{c}\text { Extruder Output } \\
(\mathrm{g} / \mathrm{min})\end{array}$ \\
\hline- & - & 250 & 35 & 73 \\
0.1 & 0.09 & 250 & 35 & 81 \\
0.5 & 0.46 & 275 & 35 & 105 \\
1.0 & 0.92 & 275 & 35 & 132 \\
2.5 & 2.31 & 350 & 35 & 200 \\
5.0 & 4.62 & 350 & 30 & \\
\hline
\end{tabular}




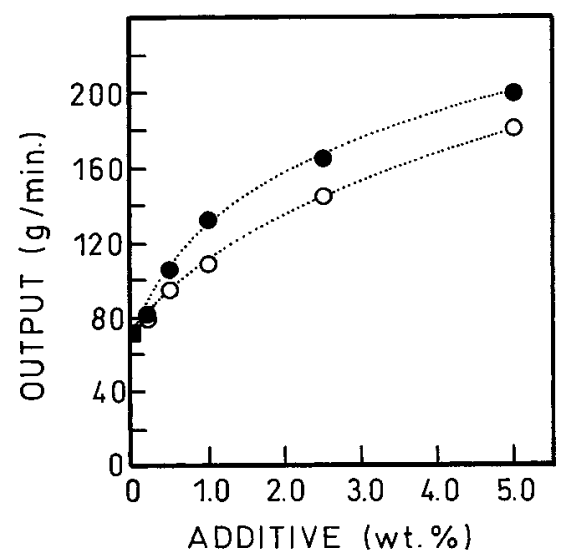

Figure 2 Extruder output as a function of the type and amount of silicone copolymer additive in HDPE blends. (○) PCL-PDMS-PCL, (๑) PDMS-PU additive.

provement of about $150 \%$. The higher efficiency of the PSU additive may be attributable to the presence of very high molecular weight PDMS $(21,000$ $\mathrm{g} / \mathrm{mol}$ ) in the copolymer when compared with that of PCL-PDMS-PCL, where the number-average PDMS molecular weight is around $2500 \mathrm{~g} / \mathrm{mol}$. The other factor, as shown in the second columns of Tables I and II, may be a higher effective PDMS amount in the PSU blends with the same total additive levels, given that PSU is made of 92.3\% by weight of PDMS oligomers, compared to PCL-PDMS-PCL, which contains only $38.5 \%$ by weight PDMS. For a better direct comparison, extruder outputs versus PDMS content in PP

Table V Blend Compositions and WaterContact Angles of Silicone-Modified PP Films

\begin{tabular}{lcc}
\hline \multicolumn{1}{c}{ Additive Type } & $\begin{array}{c}\text { Amount } \\
\text { (wt \%) }\end{array}$ & $\begin{array}{c}\text { Contact Angle } \\
\left({ }^{\circ}\right)\end{array}$ \\
\hline PP (virgin) & - & 95.0 \\
PP (extruded) & - & 97.5 \\
PCL-PDMS-PCL (pure) & 100 & 89.7 \\
PSU (pure) & 100 & 115.0 \\
PCL-PDMS-PCL & 0.10 & 98.3 \\
PCL-PDMS-PCL & 0.25 & 97.1 \\
PCL-PDMS-PCL & 0.50 & 98.5 \\
PCL-PDMS-PCL & 1.00 & 97.9 \\
PCL-PDMS-PCL & 2.50 & 99.3 \\
PCL-PDMS-PCL & 5.00 & 97.6 \\
PSU & 0.10 & 100.3 \\
PSU & 0.25 & 107.7 \\
PSU & 0.50 & 109.7 \\
PSU & 1.00 & 105.7 \\
PSU & 2.50 & 113.0 \\
\hline
\end{tabular}

Table VI Blend Compositions and Water Contact Angles of Silicone-Modified HPDE Films

\begin{tabular}{lcc}
\hline \multicolumn{1}{c}{ Additive Type } & $\begin{array}{c}\text { Amount } \\
(\text { wt } \%)\end{array}$ & $\begin{array}{c}\text { Contact Angle } \\
\left({ }^{\circ}\right)\end{array}$ \\
\hline HDPE (virgin) & - & 90.9 \\
HDPE (extruded) & - & 91.6 \\
PCL-PDMS-PCL & 1.00 & 97.7 \\
PCL-PDMS-PCL & 2.50 & 99.3 \\
PCL-PDMS-PCL & 5.00 & 98.6 \\
PSU & 0.10 & 100.7 \\
PSU & 0.25 & 101.3 \\
PSU & 0.50 & 102.5 \\
PSU & 1.00 & 101.2 \\
PSU & 2.50 & 106.7 \\
PSU & 5.00 & 110.5 \\
\hline
\end{tabular}

blends for two different additives are plotted in Figure 1.

Virgin HDPE was extruded between 150 and $185^{\circ} \mathrm{C}$ and at $250 \mathrm{rpm}$ screw speed. Under these conditions at a torque reading of $35 \mathrm{amp}$ an extruder output of $73 \mathrm{~g} / \mathrm{min}$ was obtained. Through

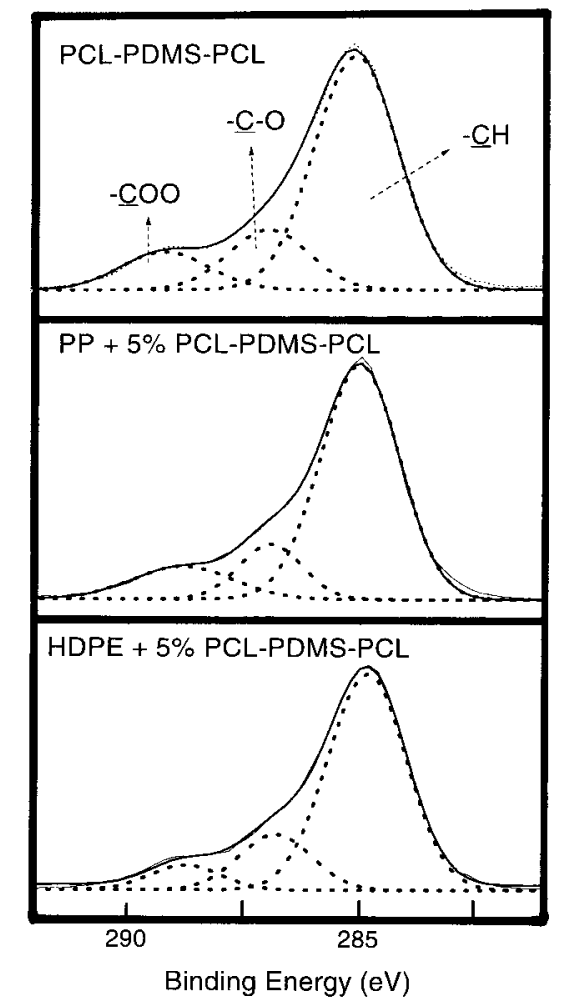

Figure $3 \mathrm{C} 1 \mathrm{~s}$ region of the XPS spectra of the PCLPDMS-PCL copolymer and blends containing 5\% of this copolymer with PP and HDPE. 
the use of silicone copolymer additives, similar to PP systems, substantial improvements in the processing behavior and extruder output of HDPE were also observed. Tables III and IV provide the resin compositions, extrusion parameters, and output improvements for PCL-PDMS-PCL and PSU-modified HDPE, respectively. For this system also, at equal additive levels, PSU seems to be more effective than PCL-PDMS-PCL, as shown in Figure 2.

\section{Surface Properties of Silicone-Modified Polyolefins}

The major aim of this study was the permanent modification of polyolefin surfaces to achieve silicone-rich, low-friction surfaces through blending with silicone copolymers for applications such as biomaterials, industrial and carpet fibers, and release films. Surface characterizations of the materials were obtained by water-contact angle measurements and ESCA studies.

\section{Water-Contact Angle Measurements}

Static water-contact angle measurement is a simple, reliable, and very informative technique for studying the surface behavior of polymeric mate- rials. By determining the angle a water drop makes with a surface, one can easily understand whether the surface has a hydrophilic or hydrophobic character. Tables V and VI give the watercontact angle data on pure PCL-PDMS-PCL and PSU copolymers and also on virgin and modified PP and HDPE films prepared in this study. Polyolefins are inherently hydrophobic and have water-contact angles of around $90^{\circ}$, as shown on Tables V and VI. Pure polydimethylsiloxane polymers are extremely hydrophobic (in fact, completely water repellant) and usually show watercontact angles well above $100^{\circ} .{ }^{17}$ In silicone copolymers the value of the water-contact angle depends on several factors. These include architecture and composition of the copolymer, average molecular weight of PDMS, nature of the organic segments, and method of sample preparation. As shown on Table $\mathrm{V}$, it is interesting to note the dramatic difference between the water-contact angle values of the additives used. PCL-PDMSPCL, which is composed of $62 \%$ by weight of somewhat polar and crystallizable polycaprolactone segments and short PDMS blocks, shows a water-contact angle of $89.7^{\circ}$. Investigation of PCL-PDMS-PCL surfaces by atomic force microscopy (AFM) indicated a lamellar surface mor-
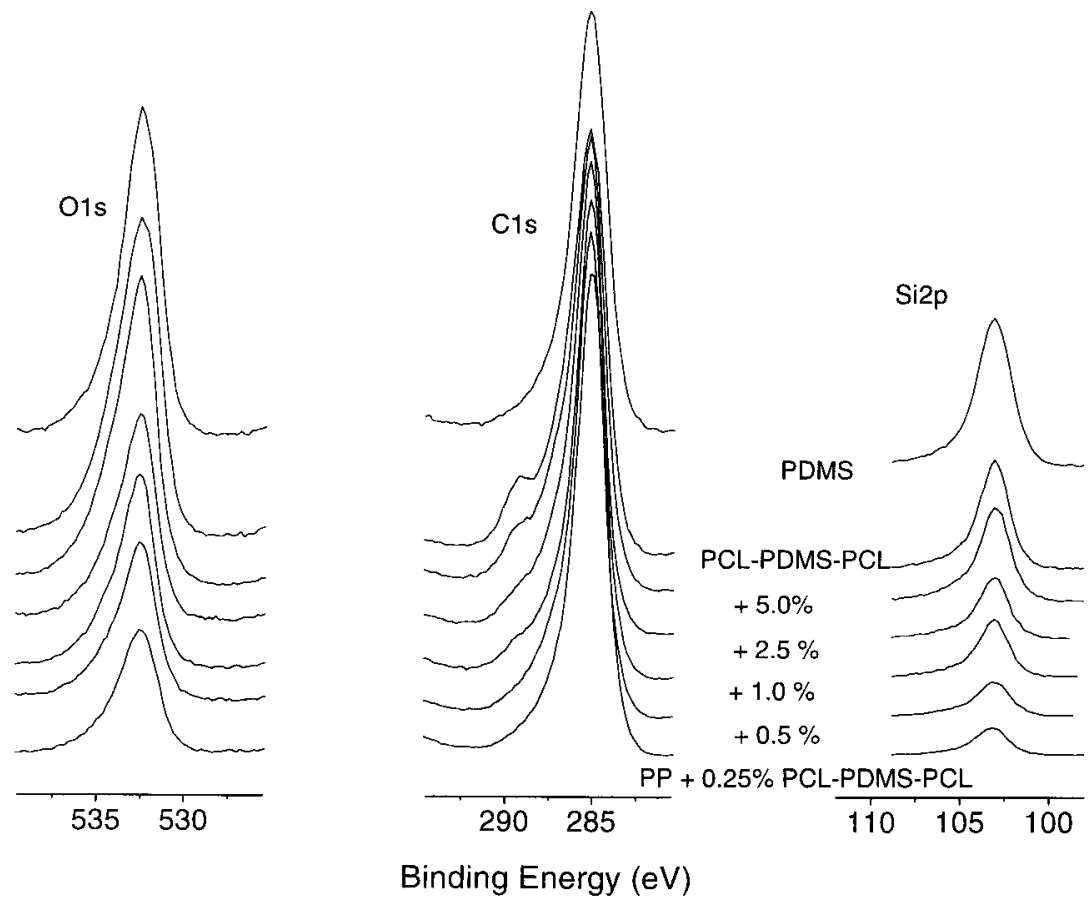

Figure $4 \mathrm{O} 1 \mathrm{~s}, \mathrm{C} 1 \mathrm{~s}$, and $\mathrm{Si} 2 \mathrm{p}$ regions of the XPS spectra of PP blends containing different amounts of the PCL-PDMS-PCL copolymer. The same regions of the XPS spectrum of PDMS are also included. 


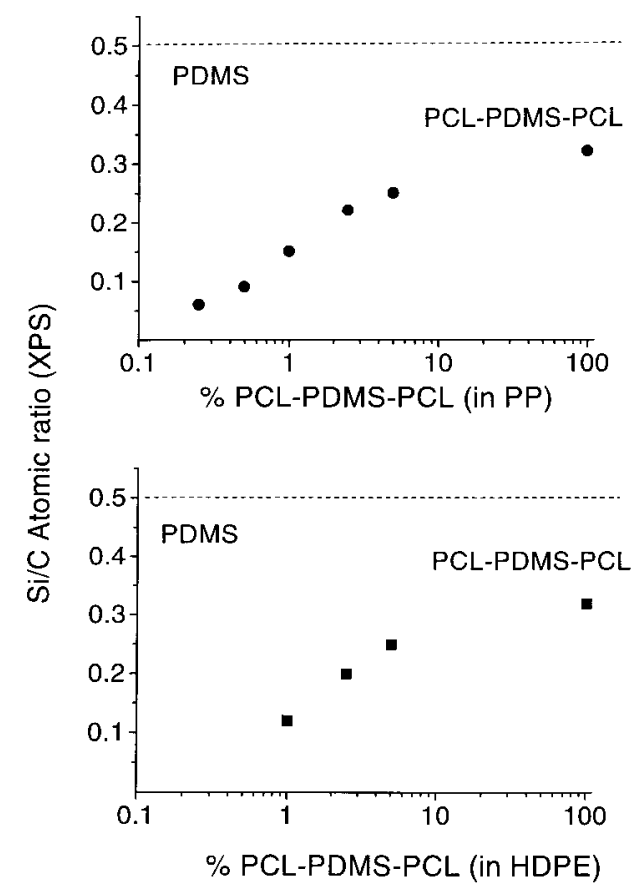

Figure $5 \mathrm{Si} / \mathrm{C}$ atomic ratios determined from the XPS measurements for $\mathrm{PP}$ and HDPE blends containing different amounts of the PCL-PDMS-PCL copolymer are plotted against the logarithm of their bulk composition.

phology, as expected. Surface topography of these copolymers, again obtained by AFM, showed PCL peaks and PDMS valleys. These results explained the low water-contact angles observed for these copolymers, given that the water droplet was mainly residing on PCL peaks. ${ }^{19}$ On the other hand PSU, which contains $92.3 \%$ by weight of PDMS with very high molecular weight, shows a water-contact angle of $115^{\circ}$, almost similar to that of pure PDMS.

As clearly shown on Table V, incorporation of small amounts of PSU into PP dramatically changes their surface behavior. Virgin and extruded PP show water-contact angles of 95.0 and $97.5^{\circ}$, respectively. The sample containing $0.1 \%$ of PSU shows a water-contact angle of $100.3^{\circ}$, which goes up to $109.7^{\circ}$ at a PSU content of $0.50 \%$ and to $113.0^{\circ}$ at $2.50 \%$ loading, almost the same as that of pure PSU film. These results show that the PP surface becomes almost completely saturated with PDMS at about $0.5 \%$ additive level. PP blends containing PCL-PDMS-PCL do not show any significant improvement in water-contact angles. As reproduced on Table VI, water-contact angle data obtained on HDPE modified with PSU and PCL-PDMS-PCL show very similar behavior to that of PP-containing systems.

\section{XPS (ESCA) Analysis of Modified Surfaces}

Water-contact angle measurements provided indirect information on the composition of polymer surfaces. X-ray photoelectron spectroscopy (XPS or ESCA) was used to obtain quantitative information on the chemical compositions of the blend surfaces. It is well known that when the incident angle is $90^{\circ}$, XPS probes a depth of approximately $5-10 \mathrm{~nm}$. On the other hand the depth probed by water-contact angle measurement is believed to be less than $1 \mathrm{~nm}$ of the surface monolayer. ${ }^{20}$

XPS studies on PP, HDPE, silicone copolymer additives, and the blends clearly show that there is dramatic enrichment of PDMS on the blend surfaces. As a dramatic example of surface enrichment by PDMS, the $\mathrm{C} 1 \mathrm{~s}$ region of the XPS spectra of pure PCL-PDMS-PCL, PP, and HDPE blends containing $5 \%$ by weight of the additive are given in Figure 3. As indicated by the dotted lines, the deconvoluted spectrum shows three $\mathrm{C} 1 \mathrm{~s}$ peaks, one centered around $285 \mathrm{eV}$ assigned to $\left(\mathrm{CH}_{2}\right)$ backbone, another at $287 \mathrm{eV}$ assigned to $(\mathrm{C}=\mathrm{O})$, and another one at $289 \mathrm{eV}$ assigned to (COO) carbon. It is interesting to note that all three spectra are almost identical. This clearly shows that at 5\% loading the surfaces of PP and HDPE films are completely covered with silicone. Figure 4 shows the O1s, C1s, and Si2p regions of PP blends containing different amounts of the PCL-PDMS-PCL copolymer additive, pure PCLPDMS-PCL, and also a pure PDMS sample. For direct comparison all peaks are stacked together. In all cases the Si2p-to-C1s intensity ratio and the deconvoluted $\mathrm{C} 1 \mathrm{~s}$ region are dominated by the copolymer. Similar behavior is also observed in HDPE blends. For a better comparison of bulk and surface compositions of PP and HDPE blends containing PCL-PDMS-PCL additives, the Si/C atomic ratios obtained from XPS spectra of the blends were plotted against the logarithm of percentage of PCL-PDMS-PCL in bulk (Fig. 5). It is interesting to note that surface compositions of blends containing $2.5 \%$ by weight of the additive are similar to that of pure PCL-PDMS-PCL. ${ }^{14}$ The O1s, C1s, and Si2p regions of XPS spectra of HDPE blends containing different amounts of PDMS-PU copolymer are shown in Figure 6. When the $\mathrm{Si} / \mathrm{C}$ atomic ratios obtained from XPS spectra are plotted against the bulk composition of these blends, as shown in Figure 7, dramatic enrichment of silicone on the surface is observed.

Direct comparison between the results of water-contact angle measurements and XPS reveals 


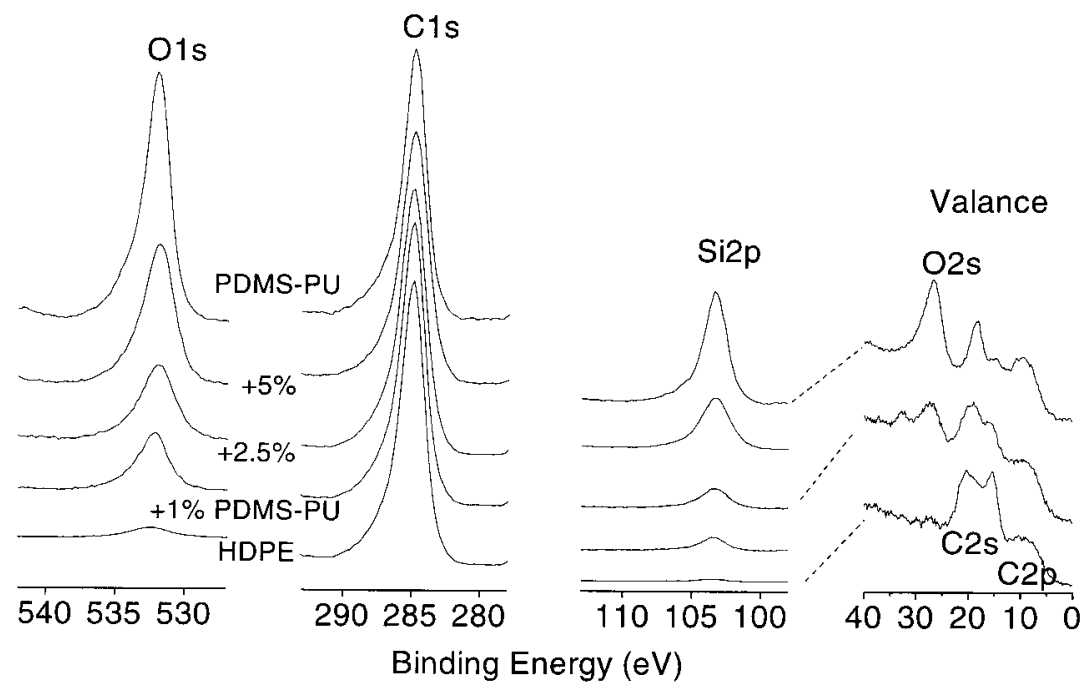

Figure 6 O1s, C1s, Si2p, and valance-band regions of the XPS spectra of HDPE blends containing 1, 2.5, and 5\% PDMS-PU copolymer. The same regions of the XPS spectrum of the copolymer are also included.

a very interesting phenomenon. As indicated before when the incident angle is $90^{\circ}$, XPS probes a depth of approximately $5-10 \mathrm{~nm}$, much deeper than that probed by water-contact angle measurements. As a result, especially for PCLPDMS-PCL-containing systems, where watercontact angles are somewhat lower, XPS data show the presence of a fairly good reservoir of silicone just underneath the surface in both PP and HDPE blends. The presence of PDMS near the surface dramatically influences two important tribological parameters, the coefficient of

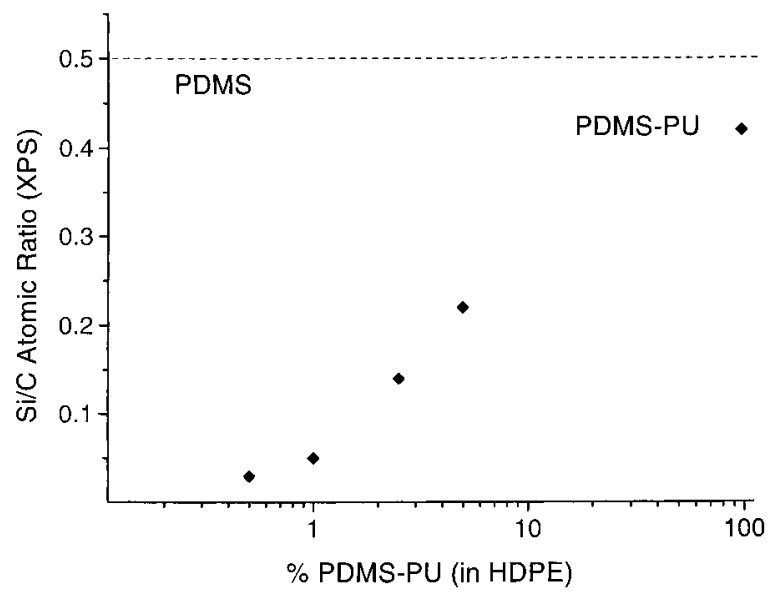

Figure $7 \mathrm{Si} / \mathrm{C}$ atomic ratios determined from the XPS measurements for HDPE blends containing different amounts of the PDMS-PU copolymer are plotted against the logarithm of their bulk composition. friction and resistance to wear. In addition, surface modifications are achieved without any noticeable change in the thermal or bulk properties of the base polymers, which are discussed in detail in the companion study. ${ }^{14}$

\section{CONCLUSIONS}

The influence of the addition of small amounts of silicone containing block copolymers on the processing behavior and surface properties of polypropylene and high-density polyethylene was investigated. Even at very small additions of 0.1 to $1.0 \%$ by weight, silicone copolymers acted as very effective processing aids, improving the extruder output more than $200 \%$, depending on the base resin and the additive used. Surface properties and compositions of the blends, determined by water-contact angle measurements and ESCA, respectively, clearly demonstrated the enhancement of silicone at the surface of the blend films.

\section{REFERENCES}

1. Van Krevelen, D. W. Properties of Polymers; Elsevier: Amsterdam, 1990.

2. Mark, J. E.; Eisenberg, A.; Graessley, W. W.; Mandelkern, L.; Koenig, J. L. Physical Properties of Polymers; American Chemical Society: Washington, DC, 1984. 
3. Garbassi, F.; Morra, M.; Occhiello, E. Polymer Surfaces: From Physics to Technology; Wiley: New York, 1994.

4. Simpson, W. G., Ed. Plastics: Surface and Finish; Royal Society of Chemists: Cambridge, UK, 1993.

5. Brydson, J. A. Plastic Materials; Butterworth-Heinemann: Oxford, UK, 1995.

6. Chan, C.-M. Polymer Surface Modification and Characterization; Hanser Verlag: Munich, Germany, 1994.

7. Noll, W. Chemistry and Technology of Silicones; Academic Press: New York, 1968.

8. Yilgor, I.; McGrath, J. E. Adv Polym Sci 1988, 86, 1.

9. Noshay, A.; McGrath, J. E. Block Copolymers: Overview and Critical Survey; Academic Press: New York, 1977.

10. Voronkov, M. G.; Mileshkevich, V. P.; Yuzhelevskii, A. Yu. The Siloxane Bond; Consultants Bureau: New York, 1978.

11. Chen, X.; Gardella, J. A., Jr. Macromolecules 1994, 27,3363 .
12. Yilgor, I. in Silicone Surfactants; Hill, R. M., Ed.; Marcel Dekker: New York, 1999; Chapter 10.

13. Yilgor, I.; Yilgor, E.; Gruning, B. Tenside Surf Detergents 1993, 30, 158.

14. Yilgor, E.; Sinmazcelik, T.; Yilgor, I. J Appl Polym Sci to appear.

15. Riffle, J. S.; Yilgor, I.; Tran, C.; Wilkes, G. L.; McGrath, J. E.; Banthia, A. K. in Epoxy Resin Chemistry II; Bauer, R. S., Ed.; ACS Symposium Series 212; American Chemical Society: Washington, DC, 1983; Chapter 2.

16. Ikada, Y.; Tumaya, Y. Lubricating Polymer Surfaces; Technomic: Lancaster, PA, 1993.

17. Owen, M. J. in Siloxane Polymers; Clarson, S. J.; Semlyen, J. A., Eds.; Prentice Hall: Englewood Cliffs, NJ, 1993.

18. Ratner, B. D.; Castner, D. G. Surface Modification of Polymeric Biomaterials; Plenum: New York, 1997.

19. Yilgor, I. Koc University, 2000, unpublished results.

20. Beamson, G.; Briggs, D. High Resolution XPS of Organic Polymers; Wiley: New York, 1992. 